\title{
Weather Matters for Energy
}


Alberto Troccoli · Laurent Dubus Sue Ellen Haupt

Editors

\section{Weather Matters for Energy}

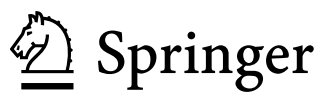


Editors
Alberto Troccoli
Pye Laboratory
Canberra, ACT
Australia
Laurent Dubus
EDF-R\&D
Chatou
France

CSIRO Marine and Atmospheric Research
Sue Ellen Haupt

Research Applications Laboratory

Haupt Associates

Boulder, $\mathrm{CO}$

USA

ISBN 978-1-4614-9220-7

ISBN 978-1-4614-9221-4 (eBook)

DOI 10.1007/978-1-4614-9221-4

Springer New York Heidelberg Dordrecht London

Library of Congress Control Number: 2013958148

\section{(C) Springer Science+Business Media New York 2014}

This work is subject to copyright. All rights are reserved by the Publisher, whether the whole or part of the material is concerned, specifically the rights of translation, reprinting, reuse of illustrations, recitation, broadcasting, reproduction on microfilms or in any other physical way, and transmission or information storage and retrieval, electronic adaptation, computer software, or by similar or dissimilar methodology now known or hereafter developed. Exempted from this legal reservation are brief excerpts in connection with reviews or scholarly analysis or material supplied specifically for the purpose of being entered and executed on a computer system, for exclusive use by the purchaser of the work. Duplication of this publication or parts thereof is permitted only under the provisions of the Copyright Law of the Publisher's location, in its current version, and permission for use must always be obtained from Springer. Permissions for use may be obtained through RightsLink at the Copyright Clearance Center. Violations are liable to prosecution under the respective Copyright Law. The use of general descriptive names, registered names, trademarks, service marks, etc. in this publication does not imply, even in the absence of a specific statement, that such names are exempt from the relevant protective laws and regulations and therefore free for general use.

While the advice and information in this book are believed to be true and accurate at the date of publication, neither the authors nor the editors nor the publisher can accept any legal responsibility for any errors or omissions that may be made. The publisher makes no warranty, express or implied, with respect to the material contained herein.

Printed on acid-free paper

Springer is part of Springer Science+Business Media (www.springer.com) 


\section{Foreword 1}

In France, the energy sector has been for a long time among the main users of meteorological, hydrological, and other climate information. Météo-France enjoys the benefit of a long-term strategic cooperation with this sector. This is why I am happy to congratulate the team of Editors of this International Conference Energy \& Meteorology (ICEM) 2011 book and to contribute to it with this short introduction.

The public and the industry expect more secure and cleaner energy, which means that the vulnerability of energy systems has to be minimized in accordance with the possible hazards impacting them, in compliance with sustainable development. Meteorological, hydrological, and other climate data are indeed essential both in day-to-day energy management and for the definition of production and distribution infrastructures. For instance, provision of electricity to users can be endangered by extreme meteorological and hydrological events such as thunderstorms with unusually strong winds, flash floods, severe icing, severe colds, heat waves, sea-level elevation associated to storm surges, floods, or other hazards.

To be protected against such events, it is not sufficient to act after their impacts have happened. It is also necessary to identify precisely the potential impacts in advance and to assess their probabilities and manage the risk through regularly updated and seamless Weather-Water and Climate Services such as the ones identified within the World Meteorological Organization (WMO)-led World Climate Conference 3 (WCC-3, 2009) and now being implemented through the Global Framework for Climate Services (GFCS-2012).

The recent advances in atmospheric sciences and in the field of energy production and management offer a huge range of new possibilities. Considering that further developments will benefit essentially from the dialog between experts from both fields, Météo-France as a member of the world meteorological community is willing to take the lead and foster this dialog within the European energy and climate agenda and even more widely. The present book will be most useful both for meteorologists and for energy practitioners to get acquainted with the recent progresses in that direction and to learn for instance from the successful cooperation between EDF and Météo-France, and many others around the globe.

The weather, water and climate community coordinated under WMO is strongly committed to improve continuously its services to the energy sector. More generally, building on the WCC-3 recommendations, WMO and many partners 
have agreed to establish a GFCS and are since October 2012 working on its implementation. The GFCS has the objective to ensure that climate information and predictions are made available to decision-makers enduring the increasing impacts of climate variability and change. A historic extraordinary session of the World Meteorological Congress took place on 29-31 October 2012, which approved the governance structure and implementation plan for the GFCS. This is a sweeping initiative to capitalize on scientific advances and roll out user-driven services starting from improved weather, water short-term forecasts to longer term climate predictions such as seasonal climate outlooks and El Niño watches, flood prediction and drought monitoring tools, and extreme events occurrence probabilities.

The GFCS is a necessary step in view to define and implement scientifically sound measures of adaptation to climate variability and climate change. It will contribute to improve the field observations in the world, to make them easily accessible under a readily utilizable form. It will also help to develop numerical modeling of the atmosphere and the Earth in general, and to produce information tailored to the users needs.

I take this opportunity to commend the work done by all the experts involved, then all the partners who contributed with resources and NATO for being the initiator and supporting the first workshop in 2008 and the first publication in 2010 which in 2011 provided the framework for the first international conference on Energy and Meteorology, conference which has assembled the material for the present publication. In view of the determination, commitment, and professionalism of the organizers of this Energy and Meteorology partnership process, I have no doubt that this endeavor, which started very simply in 2008 as an advanced research workshop will continue on a long term as a capacity building program. Météo-France was happy to host the ICEM 2013 conference, which took place in the Conference Centre of the "Meteopole" in South-West France (Toulouse, 25-28 June 2013, < https://www.icem2013.org >).

François Jacq

François Jacq studied at the École Polytechnique (Paris) and at the École Nationale Supérieure des Mines de Paris. He holds a Ph.D. in History and Sociology of Science. Before joining Météo-France in April 2009 as CEO, he was adviser to the Prime Minister on Sustainable Development, Research and Industry. He was previously a researcher at École des Mines de Paris, Director of the Department on Energy, Transportation, Environment and Natural resources in the Ministry of Research, Chief executive of the National Agency for the Management of Radioactive Waste, and Director for Energy demand and markets in the Ministry of Industry of France. Dr. Jacq is also a member of the Executive Council of the World Meteorological Organization. 


\section{Foreword 2}

When Laurent Dubus asked me to write a foreword for the book he is editing, and contributing to, with Alberto Troccoli and Sue Ellen Haupt, I accepted at once. Indeed, this is a topic which is key in my mind! I do believe that the relationships between weather, weather forecast, climate, and our job, which is to deliver safe, reliable, and affordable electricity, will increase in the future.

The interactions make sense on all aspects of our business: production, transport and distribution, and consumption. My sense is that the effect that meteorology has on energy systems can be represented by four important categories, roughly related to different meteorological time scales. I believe these four categories are as follows.

Crisis management-By improving our knowledge of severe meteorological events such as floods, strong winds, heavy snowfalls, heat and cold waves, we can better manage both demand side (with DSM-Demand Side Management) and supply side and thus we can manage crises more effectively. This means being able to access short-term forecasts but with very high resolution especially around areas of critical interest like power plants, rivers, towns, and so on. It is particularly important to try to anticipate these severe events and provide appropriate alerts, when the risk of extreme events is above a tolerable threshold, even if this means accepting some false alarms.

Day-to-day operations-My understanding about the strong relationship between electricity production, electricity use, and weather initially came through my on the ground experience. I have gained a good appreciation about the limits of forecasts so as to be able to use them properly; I worked toward improving the forecast quality and reliability to reduce the gaps between predictions and observed weather, particularly for air temperature as linked to consumption, wind speed or rainfall as linked to production. In the future, the development of electricity from renewable sources will further increase the dependence of power systems on weather variability, and hence the importance of climate uncertainty.

Planning of production facilities-Power production requires having an idea of the weather in the middle term (warm or cold weather, drought or excess in river discharge). This means not only the use of forecasts of mean weather conditions but also their probabilities. More research is required to be able to produce reliable midterm forecasts. Exactly like farmers who would like to know what cereals they can grow under certain rain patterns, we need to know if the coming summer will 
be sunny or rainy as this knowledge will shape the consumption (more or less cooling) and the balance between the different ways to produce electricity (e.g., do we need to "save" water in the reservoirs or can we release some?), also taking into account the necessary maintenance of power plants.

Facility construction and maintenance-We rely on climate knowledge to build our facilities: floods, temperature of rivers, winds etc... These data are critical in the dimensioning of plants. We use data from the past to assess the events and to define the characteristics of our plants. This point is certainly the most important for me as it requires a complete change in our relationship with stakeholders including people working on climate. The changing world, in which we currently live, including climate variations and changes, will require a serious rethinking of our "business as usual approach". We will need to expand our knowledge and practice with an eye not only on the past but also critically, on the future. We built our infrastructures to resist to the extreme events we knew through past climate data; today we need to redefine the limits between resistance and resilience of our facilities and this will require understanding of interactions with meteorological variables under climate change.

The cooperation EDF develops with the scientific community, including meteorologists, to fulfill its needs on weather and climate forecasts is more alive than ever. We need meteorologist and climatologists to increase the knowledge, provide new and more accurate data, and develop new models, forecasts, and projection at all time scales, from the real time to the end of the century.

Fulfilling our needs is only possible with a close collaboration between the weather and climate sector on the one side, and the energy sector on the other side. I do believe that this volume, and the International Conference Energy and Meteorology (ICEM) conference cycle, is an important component of such an efficient partnership.

Claude Nahon

Claude Nahon was named Group's Executive Vice President for Sustainable Development at Electricité de France (EDF) in January 2003. Prior to her appointment, she was Head of Hydro and Renewable Energies. A graduate of France's prestigious École Polytechnique, Claude Nahon has been with EDF since 1978, holding managerial positions in both generation and distribution. In addition to her responsibilities at EDF, Claude Nahon represents EDF Group in different occasions and institutions. She is Liaison Delegate of Henri Proglio in the World Business Council for Sustainable Development (WBCSD). She sits on Institut du Développement Durable et des Relations Internationales (IDDRI) and Entreprises pour l'Environnement (EPE). 


\section{Preface}

A storm is mounting. You were alerted about the approaching severe weather conditions by the weather forecaster. You're now sitting in front of your monitors trying to decide how many power units to commit. The precise power mix, whether it is more economical to run more hydro instead of wind for instance, is also key but you don't have much time to take a decision. With a combination of modeling tools and expert knowledge, you're trying to figure out whether the thick deck of clouds will make the $100 \mathrm{MW}$ solar power plant ramp down within minutes or hours. And can some of this shortfall be partly compensated by the newly installed $150 \mathrm{MW}$ wind farm? Meanwhile, gas generators will most likely be safe, but will there be enough time to start them up and avoid that horrific black out?

It has been a long day, but luckily the effects of this weather event have been well handled, as many tools were available to assess this situation and act on it efficiently. The seasonal forecast had predicted that such storms would be likely this month; thus the maintenance department had performed preventive maintenance in advance. However, it makes you wonder whether storms like this will become more frequent and impactful in the future. Already we are seeing an increasing number of meteorologically derived disasters. Warmer temperatures, as projected decades from now by climate models, will very likely bring even more severe events. It is almost a no-brainer to factor these climate effects into energy sector risk management decision-making. But exactly how to do this may not be straightforward.

It is the purpose of this book to provide the meteorological knowledge and tools to improve the risk management of energy industry decisions, ranging from the longterm finance and engineering planning assessments to the short-term operational measures for scheduling and maintenance. Most of the chapters in this book are based on presentations given at the inaugural International Conference Energy and Meteorology (ICEM), held in the Gold Coast, Australia, 8-11 November 2011 (see http://www.icem2011.org). The main aim of the conference was to strengthen the link between Energy and Meteorology, so as to make meteorological information more relevant to the planning and operations of the energy sector. The ultimate goal would be to make the best use of weather and climate data in order to achieve a more efficient use of energy sources. This book seeks to realize the same objective.

It is worth highlighting the close connection, in terms of temporal and spatial scales, between decisions in the energy industry on the one hand and natural 
meteorological events on the other. Indeed, decisions in the energy industry extend from the tiny temporal scales related to electrical instabilities, to the short-term typical of supply and demand balancing, to the longer terms typical of maintenance through to planning. Similarly, meteorological phenomena occur over essentially all time and space scales from the tiny scales of turbulence, to the shortterm and small-scale events such as tornadoes, to the longer/larger hurricanes, through to climate change via El Niño. Often there is a strong link between a particular meteorological phenomenon and its implications for the energy sector. Thus, for instance, a hurricane, which typically lasts several days and affects an area of a few thousand kilometres, will be factored in energy operational and maintenance decisions over the span of a number of days, and with an advance notice of several days (hurricanes can be predicted several days in advance).

The book is structured to emphasize the role of the energy industry in terms of meteorological requirements. Indeed, unlike the more standard approach, which begins by presenting meteorological information, as if the latter was in search of a purpose, here we have genuinely attempted to put energy in the driver's seat. Such order is also reflected in the titles of the book parts, as with Why Should the Energy Industry be Concerned About Weather Patterns? of Part One.

There is no doubt that Energy and Meteorology is a burgeoning inter-sectoral discipline. It is also clear that the catalyst for the stronger interaction between these two sectors is the renewed and fervent interest in renewable energies, especially wind and solar power. This connection is also apparent from the content of the book. However, it must be realised that weather and climate information is also critical to managing the energy supply from other energy sectors (e.g., offshore oil operations) as well as understanding and estimating energy demand. We have tried to stress this broader dependency in various parts of the book.

The book could not have come together without the ICEM 2011 meeting. Hence, we are indebted to the superb support of Elena Bertocco, the extraordinary organizational role of Aurélie Favennec, the efficient work of the steering and scientific organising committee, and the keen contributions of the conference delegates during an intense and fascinating week along the beautiful ocean shore of the Gold Coast of Australia.

It is a great pleasure to acknowledge the tremendous assistance of Danielle Stevens who has indefatigably and very diligently been assembling the book, even when prodding was needed to obtain responses from chapter authors. We are also indebted to Pierre Audinet for his strong support in shaping this book and for suggesting what we believe is an appropriate and attractive book title. We also wish to thank all the authors of the book for chipping in and helping to carry out thorough reviews of all chapters of this book.

We do hope you will enjoy this book. Happy reading!

Alberto Troccoli

Laurent Dubus Sue Ellen Haupt 


\section{Contents}

\section{Part I Why Should the Energy Industry be Concerned}

About Weather Patterns?

A New Era for Energy and Meteorology . . . . . . . . . . . . . . . . 3

Beverley F. Ronalds, Alex Wonhas and Alberto Troccoli

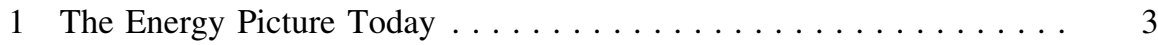

2 Vulnerability of Energy Systems to the Current Climate . . . . . . . . 6

3 Transforming Our Energy System: Challenges and Opportunities . . . . 8

4 A Step-Change in Meteorology and Energy Linkages . . . . . . . . . . 10

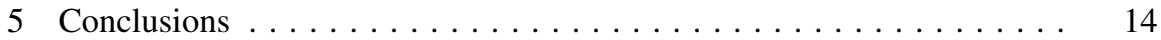

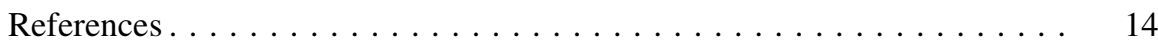

Climate Risk Management Approaches in the Electricity Sector:

Lessons from Early Adapters. . . . . . . . . . . . . . . . . . . . 17

Pierre Audinet, Jean-Christophe Amado and Ben Rabb

1 The Need to Strengthen the Resilience of Electricity Systems in Developing Countries ................ 20

2 Existing Research on Climate Data and Information, Associated Risks, and Adaptation Solutions . . . . . . . . . . 23

3 Early Adaptation Efforts in the Electricity Sector . . . . . . . . . . 33

4 Current Focus of Adaptation Efforts and Gaps . . . . . . . . . . . . . . 49

5 Lessons Learnt and the Way Forward ................ 56

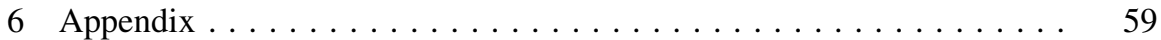

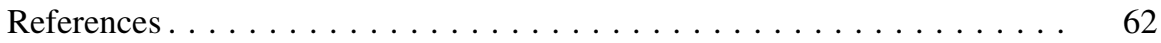

Climatic Changes: Looking Back, Looking Forward . . . . . . . . . . . 65

Alberto Troccoli

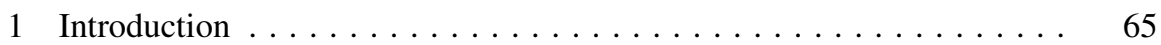

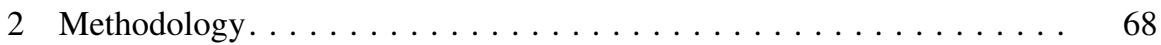

3 Historical Climate Relevant to Energy . . . . . . . . . . . . . . . . 73

4 Projected Climate Changes Relevant to Energy . . . . . . . . . . . . . . 79

5 Extreme Weather Events Relevant to Energy . . . . . . . . . . . . 85

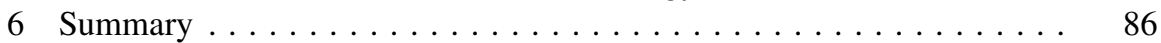

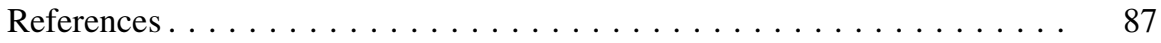


Renewable Energy and Climate Change Mitigation:

An Overview of the IPCC Special Report.

Ralph E. H. Sims

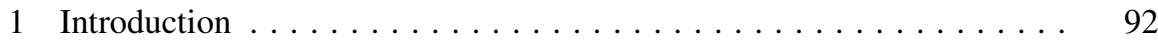

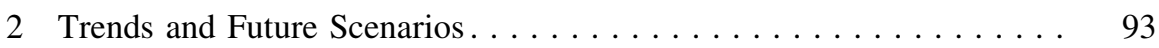

3 Climate Change Impacts on Renewable Resources . . . . . . . . . . 96

4 Costs . . . . . . . . . . . . . . . . . . . . . . . . 99

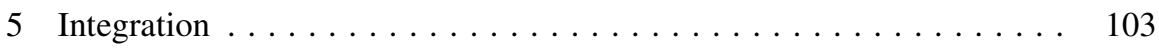

6 Sustainable Development . . . . . . . . . . . . . . . . . 106

7 Co-Benefits, Barriers and Policies . . . . . . . . . . . . . . . . 108

8 Conclusions ............................. 109

References................................. 110

\section{Part II How is the Energy Industry Meteorology-Proofing Itself?}

Improving Resilience Challenges and Linkages of the Energy

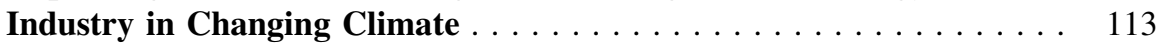

Shanti Majithia

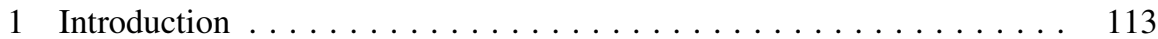

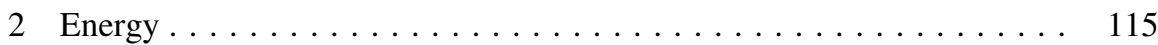

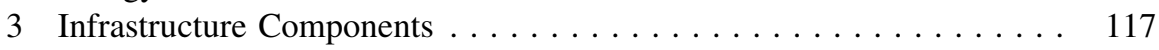

4 Potential Risk to the Infrastructure. . . . . . . . . . . . . . . . . 119

5 Business Preparedness: Infrastructure and Corporate Resilience . . . . 121

6 Information Gap Analysis in Climate Science . . . . . . . . . . . 127

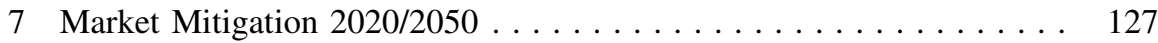

8 Linking Meteorology, Climate and Energy . . . . . . . . . . . . 128

9 Conclusion . . . . . . . . . . . . . . . . . . . . . . . . . . 129

References............................... 130

Combining Meteorological and Electrical Engineering Expertise

to Solve Energy Management Problems . . . . . . . . . . . . . . . 133

Giovanni Pirovano, Paola Faggian, Paolo Bonelli, Matteo Lacavalla,

Pietro Marcacci and Dario Ronzio

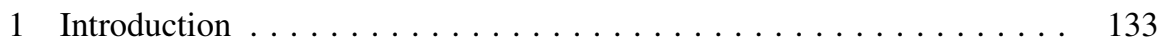

2 The Meteorological Demand from Energy Community . . . . . . . . 134

3 Climate Change Impact on the Electric System. . . . . . . . . . . . . 135

4 Forecasting "Weather Energy" . . . . . . . . . . . . . . . . . . 139

5 Weather Risks for the Power System . . . . . . . . . . . . . . . 142

6 Conclusion ............................. 152

References.............................. 153 


\section{Weather and Climate Impacts on Australia's National}

Electricity Market (NEM) .

Tim George and Magnus Hindsberger

1 Introduction . . . . . . . . . . . . . . . . . . . . . . . . . . . . . 155

2 Setting the Scene. . . . . . . . . . . . . . . . . 157

3 Characteristics of Weather-Dependent Generation . . . . . . . . . . . . . 158

4 Operational Considerations . . . . . . . . . . . . . . . . . . . . . . . . 164

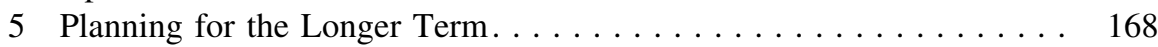

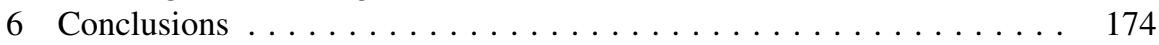

References............................. 175

Bioenergy, Weather and Climate Change in Africa:

Leading Issues and Policy Options . . . . . . . . . . . . . . . . . . . 177

Mersie Ejigu

1 Introduction . . . . . . . . . . . . . . . . . . . . . . 177

2 Africa's Energy Profile and Vulnerability to Climate Change . . . . . . . 178

3 Bioenergy Vis-à-Vis Other Renewables:

The Significance of Weather. . . . . . . . . . . . . . . . . 183

4 Bioenergy: Climate Opportunities and Risks . . . . . . . . . . . . . . . . 184

5 The Direct and Indirect Impacts of Weather/Climate Change . . . . . . . 187

6 Main Policy Issues and Options . . . . . . . . . . . . . . . . 191

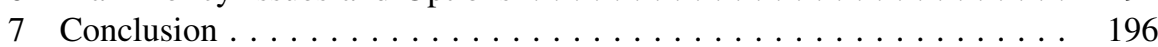

References............................. 196

\section{Part III What can Meteorology Offer to the Energy Industry?}

\section{Weather and Climate Information Delivery within}

National and International Frameworks. . . . . . . . . . . . . . . . 201 John W. Zillman

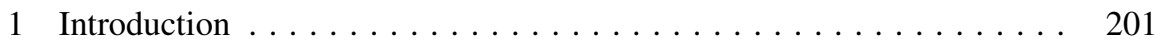

2 The Nature of Weather and Climate . . . . . . . . . . . . . . 202

3 Meteorological and Related Services . . . . . . . . . . . . . . . . . . . 204

4 The National Meteorological Service System . . . . . . . . . . . . . . . . . . 208

5 The Global Framework for Meteorological Service Provision . . . . . . 211

6 Future Directions. . . . . . . . . . . . . . . . . . . . 214

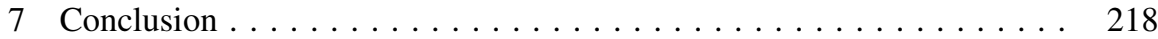

References............................ 218

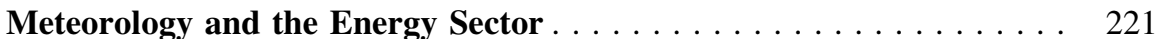

Geoff Love, Neil Plummer, Ian Muirhead, Ian Grant and Clinton Rakich

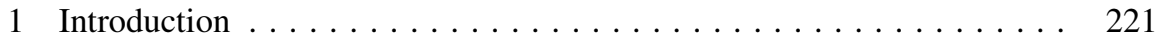

2 Factors Affecting Electricity Production. . . . . . . . . . . . . . 222 
3 The Energy Sector's Requirement for Meteorological Services . . . . . . 224

4 Overview: Uses of Meteorological Information in the Energy Sector . . . . . . . . . . . . . . . . . . . . 227

5 An Energy Sector Case Study: Solar Resource Assessment . . . . . . . 229

6 A New Global Information Service . . . . . . . . . . . . . . . . . . 232

7 Components of the Global Framework for Climate Services . . . . . . . 233

8 Some Concluding Remarks . . . . . . . . . . . . . . . . . . . . . 234

References............................... 234

Earth Observation in Support of the Energy Sector . . . . . . . . . . . 237

Pierre-Philippe Mathieu

1 The View from Space: A Unique Perspective to Help the Energy Sector . . . . . . . . . . . . . . . . . . . . . . . . . . 237

2 EO Demonstration Pilot Projects in Support of the Energy Sector . . . 242

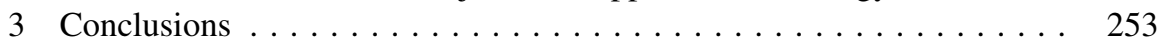

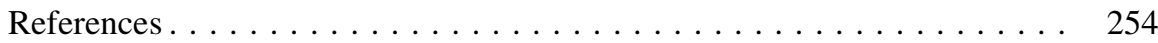

Emerging Meteorological Requirements to Support High

Penetrations of Variable Renewable Energy Sources: Solar Energy. . . 257

David S. Renné

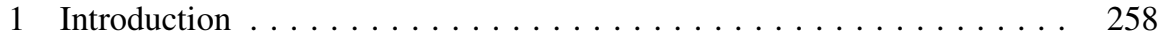

2 Global Trends in PV Development . . . . . . . . . . . . . . 258

3 Perspectives from the Utility Industry . . . . . . . . . . . . . . . 260

4 Challenges for the Solar Resource Community . . . . . . . . . . . . . . . 262

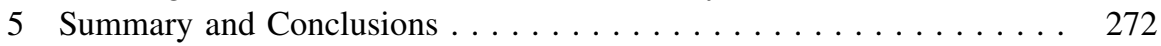

References........................... 273

Current Status and Challenges in Wind Energy Assessment . . . . . . . 275

Sven-Erik Gryning, Jake Badger, Andrea N. Hahmann

and Ekaterina Batchvarova

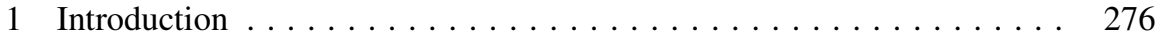

2 Global Wind Resources . . . . . . . . . . . . . . . . . . . . 276

3 Dynamical Downscaling for Wind Applications

Using Meteorological Models . . . . . . . . . . . . . . . . . . . . 283

4 Summary and Outlook . . . . . . . . . . . . . . . . . . . . 291

References............................... 292

Wind Power Forecasting . . . . . . . . . . . . . . . . . . . . . . 295

Sue Ellen Haupt, William P. Mahoney and Keith Parks

1 The Need for Renewable Energy Power Forecasts. . . . . . . . . . . . . . . 295

2 A System's Approach to Forecasting . . . . . . . . . . . . . . . . . . . . . 297

3 Numerical Weather Prediction. . . . . . . . . . . . . . . . . . . . 300

4 Statistical Postprocessing . . . . . . . . . . . . . . . . . 302 


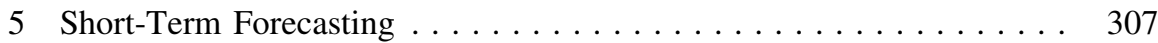

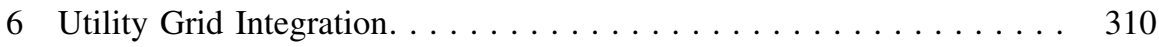

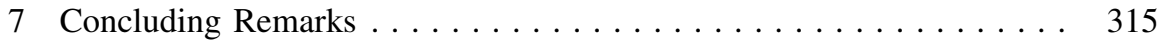

References........................... 316

Regional Climate Modelling for the Energy Sector . . . . . . . . . . . . . 319 Jack Katzfey

1 Introduction . . . . . . . . . . . . . . . . . . . . . . . 319

2 Methods/Techniques ...................... 323

3 Application of Regional Climate Models for the Energy Industry . . . 329

4 Summary and Discussion . . . . . . . . . . . . . . . . . 330

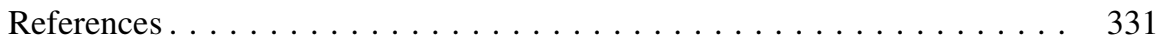

In Search of the Best Possible Weather Forecast

for the Energy Industry. . . . . . . . . . . . . . . . . . . . 335

Pascal Mailier, Brian Peters, Devin Kilminster and Meghan Stephens

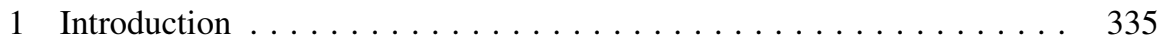

2 What Makes a 'Good' Forecast? . . . . . . . . . . . . . . 336

3 The Fallacy of Accuracy . . . . . . . . . . . . . . . . . 338

4 The Value of a Probability Forecast. . . . . . . . . . . . . . . . . 341

5 Best Versus Most Useful . . . . . . . . . . . . . . . . . . . . . 347

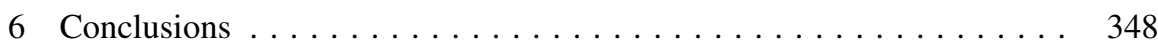

References.............................. 349

\section{Part IV How is the Energy Industry Applying State-of-the-Science Meteorology?}

\section{A Probabilistic View of Weather, Climate,}

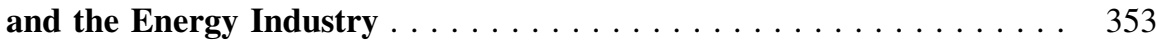

John A. Dutton, Richard P. James and Jeremy D. Ross

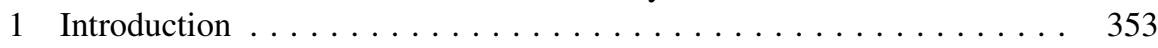

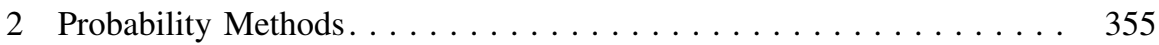

3 Probability Forecasts of Atmospheric Events . . . . . . . . . . . . . . 357

4 Modeling Probabilities of Business Results. . . . . . . . . . . . . . . . 368

5 Atmospheric Informatics . . . . . . . . . . . . . . . . . . 373

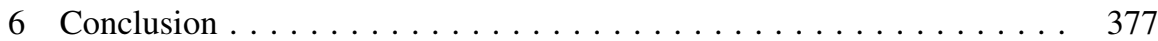

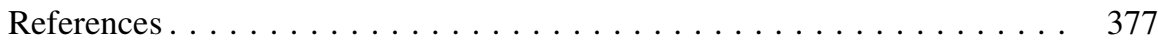

Weather and Climate and the Power Sector: Needs, Recent

Developments and Challenges . . . . . . . . . . . . . . . . . . . . 379

Laurent Dubus

1 Introduction: The Power Sector is Increasingly

Weather Dependent . . . . . . . . . . . . . . . . . . . . . . . . 380 
2 Probabilistic Temperature Forecasts of a Few Days to One Month . . 383

3 Improvement in Monthly River Flow Forecasts. . . . . . . . . . . . . . . . . . . . 387

4 Some Challenging Problems . . . . . . . . . . . . . . . . . . . . . 390

5 Conclusion: Importance of Collaboration Between

Users and Providers . . . . . . . . . . . . . . . . . . . . . . . 396

References........................... 396

Unlocking the Potential of Renewable Energy with Storage . . . . . . . 399

Peter Coppin, John Wood, Chris Price, Andreas Ernst and Lan Lam

1 Introduction . . . . . . . . . . . . . . . . . . . . . . . . . . . 399

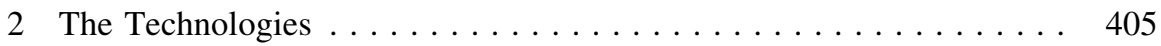

3 A Case Study: Wind Farm Smoothing . . . . . . . . . . . . . . . . . . . . 407

4 A More Advanced Algorithm . . . . . . . . . . . . . . . . . . . 410

5 Advanced Algorithm Results. . . . . . . . . . . . . . . . 410

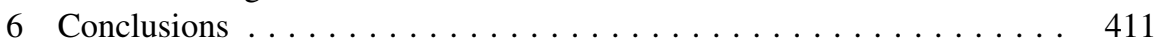

References............................. 412

Improving NWP Forecasts for the Wind Energy Sector . . . . . . . . . . 413

Merlinde Kay and Iain MacGill

1 Introduction . . . . . . . . . . . . . . . . . . . . . . . . 414

2 Wind Farm Data and the Forecast Model Used in This Study. . . . . . 415

3 Bias Correction Methodology . . . . . . . . . . . . . . . 418

4 Results ............................ 420

5 Conclusion ............................ 427

References............................... 427

Overview of Irradiance and Photovoltaic Power Prediction . . . . . . . 429

Elke Lorenz, Jan Kühnert and Detlev Heinemann

1 Introduction . . . . . . . . . . . . . . . . . . . . . . . 429

2 Typical Outline of PV Power Prediction Systems . . . . . . . . . . . 431

3 Irradiance Forecasting . . . . . . . . . . . . . . . . . . 433

4 Evaluation of Irradiance Forecasts . . . . . . . . . . . . . . . . . . . 440

5 PV Power Forecasting . . . . . . . . . . . . . . . . . . 447

6 Evaluation of PV Power Forecasts. . . . . . . . . . . . . . . . . 450

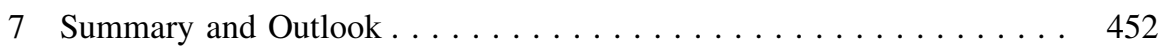

References........................... 453

Spatial and Temporal Variability in the UK Wind Resource:

Scales, Controlling Factors and Implications

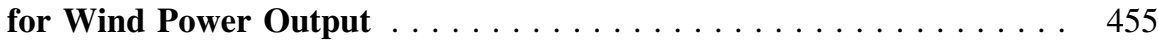

Steve Dorling, Nick Earl and Chris Steele

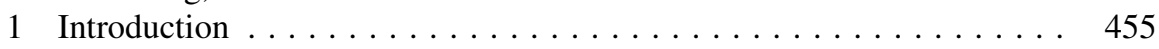

2 Tools ........................... 456 
3 Analysis of $10 \mathrm{~m}$ Station Measurements. . . . . . . . . . . . . . . 457

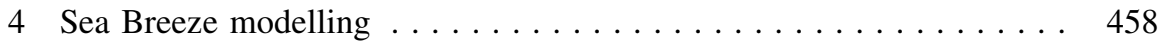

5 Conclusions . . . . . . . . . . . . . . . . . . . . . . . . . . . 464

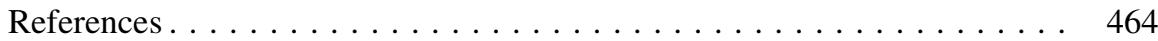

Reducing the Energy Consumption of Existing Residential

Buildings, for Climate Change and Scarce Resource

Scenarios in 2050

John J. Shiel, Behdad Moghtaderi, Richard Aynsley and Adrian Page

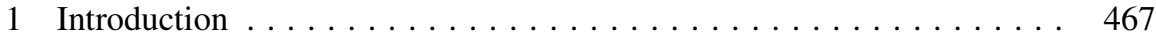

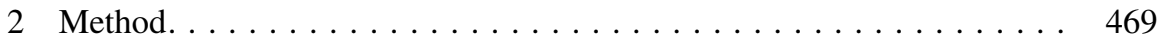

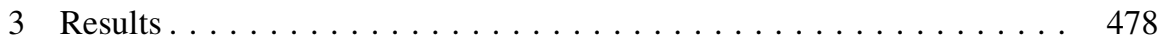

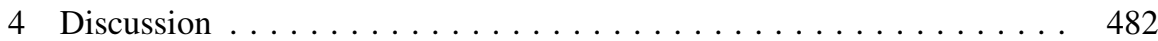

5 Conclusion ........................... 489

References............................. 490

\section{Part V Concluding Chapter}

Energy and Meteorology: Partnership for the Future . . . . . . . . . . . 497

Don Gunasekera, Alberto Troccoli and Mohammed S. Boulahya

1 Introduction . . . . . . . . . . . . . . . . . . . . . . . 497

2 Current Forms of Meteorological Service Provision. . . . . . . . . . . . 500

3 Challenges Faced by the National Meteorological and Hydrological Services . . . . . . . . . . . . . . . . . . 503

4 Energy Services: Current and Future Trends . . . . . . . . . . . . . . . 505

5 Energy and Meteorology Interaction . . . . . . . . . . . . . . . . 506

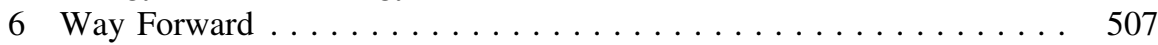

References............................. 509

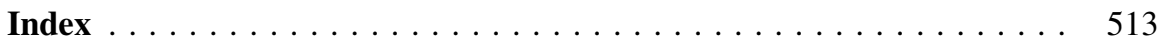

